\title{
Influence of varieties and clones and planting density on dying out willow bushes in a 8-year
}

\author{
Wpływ odmian i klonów oraz gęstości sadzenia \\ na zamieranie karp wierzby krzewiastej w 8-letnim cyklu uprawy
}

\author{
Leszek Styszko*, Diana Fijałkowska
}

\begin{abstract}
Summary
Field studies were conducted in the experimental field of Koszalin University of Technology in Kościernica, in the years 2007-2014 using 10 varieties of willow at 3 planting densities of cuttings ( 15020 pcs/ha, 22134 pcs/ha and 33200 pcs/ha). Cuttings were planted in 2007 and one year old shoots were harvested in winter 2007/2008. In autumn of 2010 half of the plot was harvested, and in November 2011 the whole plot was harvested. Withering of basket willow bushes was highly affected by the age of cultivation, planting density cuttings and their interaction and less affected by the variety and frequency of harvesting of the shoots in the first cycle. After the fourth growing season $6.6 \%$ of bushes withered (on the average), and a large increase of the number of dead bushes on the plot occurred in the next vegetation periods (6th $-20.7 \%$, 8th $-36.1 \%$ ). The varieties were classified in terms of susceptibility to withering: very strong - Olof (22.9\%), strong - Start (19.0\%) and Jorr (17.9\%), medium - 1047 (13.2\%), 1054 (12.9\%), 1047D (12.8\%), Sprint (12.1\%), Turbo (11.8\%) and Tordis (10.5\%) and small - Ekotur (6.5\%). The increase in the density of cuttings planting resulted in increased withering of willow bushes. In objects harvested 1 time within the first 4 -year cycle $12.2 \%$ withered on the average and in objects harvested 2 times $-15.7 \%$.
\end{abstract}

Key words: field studies; willow; bushes withering; cultivars; clones; harvest; planting density

\section{Streszczenie}

Badania polowe przeprowadzono na polu Politechniki Koszalińskiej w Kościernicy w latach 2007-2014 z 10 odmianami wierzby przy 3 gęstościach sadzenia zrzezów (15 020 szt./ha, 22134 szt./ha i 33200 szt./ha). Zrzezy wysadzono w 2007 roku, a jednoroczne pędy skoszono zimą 2007/2008. Jesienią 2010 roku skoszono połowę poletka, a w listopadzie 2011 roku - skoszono całe poletko. Na zamieranie karp wierzby duży wpływ miał wiek uprawy, gęstość sadzenia zrzezów i ich współdziałanie, a mniejsze - odmiany i częstotliwość zbioru pędów w I rotacji. Po czwartej wegetacji przeciętnie zamarło 6,6\% karp wierzby, a duży wzrost ilości martwych karp na poletku wystąpił w następnych wegetacjach (6. - 20,7\%, 8. - 36,1\%). Odmiany zakwalifikowano pod względem skłonności do zamierania: bardzo silne - Olof (22,9\%), silne - Start (19,0\%) i Jorr (17,9\%), średnie - 1047 (13,2\%), 1054 (12,9\%), 1047D (12,8\%), Sprint $(12,1 \%)$, Turbo $(11,8 \%)$ i Tordis $(10,5 \%)$ oraz małe - Ekotur $(6,5 \%)$. Wzrost gęstości sadzenia zrzezów spowodował nasilenie zamierania karp wierzby. Na obiektach z 1-krotnym koszeniem w pierwszej 4-letniej rotacji zamarło przeciętnie 12,2\% karp, a przy 2-krotnym-15,7\%.

Słowa kluczowe: badania polowe; wierzba; zamieranie karp; odmiany; klony; zbiór; gęstość sadzenia

\author{
Politechnika Koszalińska \\ Katedra Biologii Środowiskowej, Zakład Roślin Energetycznych \\ Śniadeckich 2, 75-453 Koszalin \\ *corresponding author: Istyszko@wbiis.tu.koszalin.pl
}




\section{Wstęp / Introduction}

Na plantacjach wierzby uprawianej na cele energetyczne znaczenie ma ilość karp na hektarze w całym 25-letnim cyklu, gdyż corocznie ich obsada maleje, a to wpływa ograniczająco na plon biomasy pędów. Badania Stolarskiego (2009) wykazały, że zamieranie karp wierzby w pierwszym 3-letnim cyklu uprawy na madzie bardzo ciężkiej zależało od odmiany, gęstości sadzenia oraz częstotliwości zbioru, ale nie przekraczało 10\% założonej obsady. W badaniach autorów, wykonanych na glebie lekkiej o głębokim poziomie wody gruntowej, ale przy dostatku opadów, w pierwszym 2- lub 4-letnim cyklu uprawy zamarło mniej niż 10\% karp, ale już w siódmej wegetacji klony miały zróżnicowaną ilość martwych karp na poletku (od 10 do 90,8\%) (Styszko i wsp. 2013). W innych badaniach wykazano, że wzrost dawki nawożenia azotem do $180 \mathrm{~kg} / \mathrm{ha}$ w stosunku do obiektów bez nawożenia spowodował nasilenie zamierania karp wierzby, a dodatkowo na obiektach z 2-krotnym koszeniem w pierwszej 4-letniej rotacji zamarło przeciętnie 2,5-krotnie więcej karp niż przy 1-krotnym koszeniu (Styszko i Ignatowicz 2014).

Celem badań była ocena wpływu wieku uprawy, gęstości sadzenia zrzezów i zróżnicowanej częstotliwości zbioru w I czteroletniej rotacji na zamieranie karp u 7 odmian i 3 klonów wierzby.

\section{Materiały i metody / Materials and methods}

W kwietniu 2007 roku na glebie lekkiej, przez 10 lat odłogowanej, o bardzo głębokim poziomie wody gruntowej (18 m od poziomu gruntu) na polu doświadczalnym Politechniki Koszalińskiej w Kościernicy, założono doświadczenie z 7 odmianami i 3 klonami wierzby ze zróżnicowaną gęstością sadzenia zrzezów. Pole to zlokalizowane było na kompleksie żytnim dobrym (5), klasy bonitacyjnej IVa, o składzie granulometrycznym w profilu glebowym pgl·ps:gl. W roku założenia doświadczenia polowego gleba zawierała następujące ilości przyswajalnych makroskładników w 100 gramach: $\mathrm{P}_{2} \mathrm{O}_{5}-16,5 \mathrm{mg}, \mathrm{K}_{2} \mathrm{O}-3,5 \mathrm{mg}$ i $\mathrm{MgO}-1,7 \mathrm{mg}$, a pH gleby wynosiło od 4,8 na głębokości 0-20 cm do 5,8 - w warstwie $21-40 \mathrm{~cm}$. Corocznie stosowano jednolicie na całym doświadczeniu nawożenie mineralne $\mathrm{w}$ dawkach makroskładnika $\mathrm{w} \mathrm{kg/ha:} \mathrm{N}-120$, $\mathrm{P}-9, \mathrm{~K}-42, \mathrm{Ca}-11, \mathrm{~S}-15$. Doświadczenie składało się z okresu przygotowawczego (2007 rok), w którym wysadzono zrzezy wierzby o długości 25 cm, a zimą 2007/2008 skoszono jednoroczne pędy. W pierwszym cyklu, w listopadzie 2010 roku skoszono połowę poletka, a w listopadzie 2011 roku - całe poletko. Na istniejących nasadzeniach wierzby w 2008 roku założono doświadczenie ścisłe, metodą losowanych podbloków w układzie zależnym w trzech powtórzeniach, gdzie podblokami I rzędu były trzy gęstości sadzenia zrzezów (15 020 szt./ha, 22134 szt./ha i 33200 szt./ha), a II rzędu - 7 odmian (Start, Sprint, Turbo, Ekotur, Olof, Jorr i Tordis) i 3 klony (1047, 1054, 1047D) wierzby. Poletka miały powierzchnię $25,3 \mathrm{~m}^{2}$, na której wysadzano po 38, 56 i 84 zrzezy wierzby w dwóch rzędach. Na lata 2012-2015 przypadł drugi 4-letni cyk1 odrastania pędów wierzby. Każdego roku oceniano zamieranie karp wierzby. Dla tej cechy wykonano analizę struktury komponentów wariancyjnych, a istotność źródeł zmienności oceniono testem F.

\section{Wyniki i dyskusja / Results and discussion}

Wegetacja wierzby w latach 2007-2014 rozpoczynała się w drugiej połowie kwietnia, a jej przebieg zależał od rozkładu temperatur i opadów. Dane o opadach oraz współczynniku hydrotermicznym Sielianinowa w latach 2007-2014 zestawiono dla Koszalina według Instytutu Meteorologii i Gospodarki Wodnej - Państwowego Instytutu Badawczego w tabeli 1. (GUS 2010, 2014). Pole doświadczalne w Kościernicy oddalone było o $20 \mathrm{~km}$ od Koszalina w kierunku południowym. W okresie trwania badań w Koszalinie opady wyniosły od 588,9 mm w 2014 roku do $1014 \mathrm{~mm}$ w $2007 \mathrm{roku}$, a podczas wegetacji wierzby (IV-X), od $387 \mathrm{~mm} \mathrm{w} 2014$ roku do $646 \mathrm{~mm}$ w 2007 roku (tab. 1). Charakterystyka przebiegu pogody na podstawie opadów okazała się niewystarczająca, ze względu na ich nierównomierny rozkład (tab. 1). Hydrotermiczne warunki ekstremalne (skrajnie suche i bardzo suche oraz bardzo wilgotne i skrajnie wilgotne) oznaczone współczynnikiem Sielianinowa $(\mathrm{K})$ mieszczą się w przedziałach $<0,7$ oraz $>2,5$ (Skowera i Puła 2004). Za okres wegetacji współczynnik ten wahał się w granicach od 1,24 w 2014 roku do 2,20 w 2007 roku. Warunki skrajnie suche i bardzo suche wystąpiły w kwietniu w latach: 2009, 2010 i 2011, w maju w latach: 2008 i 2012 oraz w lipcu 2014 roku. Warunki bardzo wilgotne wystapiły w kwietniu w latach: 2008 i 2014, w 2007 roku w czerwcu oraz we wrześniu i październiku 2012 roku, a skrajnie wilgotne w lipcu 2007 roku, w maju i sierpniu 2010 roku oraz w październiku 2009 roku.

Strukturę procentową efektów głównych oraz ich interakcji w odniesieniu do udziału w łanie wierzby martwych karp, podano w tabeli 3. Na podkreślenie zasługuje dominujące znaczenie lat odrastania pędów, a nieco mniejsze znaczenie - odmian i klonów oraz gęstości sadzenia, a względnie małe - częstotliwości koszenia. Ten ostatni czynnik, wiąże się z częstotliwością zbioru w pierwszej 4-letniej rotacji, a mianowicie na I rzędzie każdego poletka dokonano 2-krotnie zbioru w odstępie 1 roku (listopad 2010 i 2011 roku, tj. po trzeciej i po czwartej wegetacji), a na II rzędzie koszono tylko 1-krotnie (listopad 2011 roku, tj. po czwartej wegetacji).

Wpływ wieku plantacji oznaczony jako lata odrastania pędów, odmian i klonów oraz współdziałania lat zestawiono $\mathrm{w}$ tabeli 4 . Do czwartego roku odrastania pędów przeciętnie było $6,6 \%$ zamarłych karp, a wzrost ilości martwych karp na poletku nastąpił w szóstej (2012 rok) i ósmej wegetacji (2014 rok), mimo względnie korzystnego rozkładu opadów w 2012 roku oraz przeciętnego w latach 2013-2014. W 2013 roku wystąpiły warunki hydrotermiczne suche do dość suchych w maju, lipcu i sierpniu, a w 2014 roku - w czerwcu, wrześniu i październiku. Powyżej 10\% zamarłych karp na poletku stwierdzono już $\mathrm{w}$ pierwszym roku uprawy u odmiany Olof, w drugim - u odmiany Jorr, w szóstym roku 
Tabela 1. Opady w Koszalinie w latach 2007-2014 według Głównego Urzędu Statystycznego (GUS) [mm]

Table 1. Precipitation in Koszalin in the years 2007-2014 according to Central Statistical Office (CSO) [mm]

\begin{tabular}{|c|c|c|c|c|c|c|c|c|}
\hline \multirow{2}{*}{$\begin{array}{l}\text { Miesiąc } \\
\text { Month }\end{array}$} & \multicolumn{8}{|c|}{$\begin{array}{l}\text { Opady w latach - Precipitation in the years } \\
{[\mathrm{mm}]}\end{array}$} \\
\hline & 2007 & 2008 & 2009 & 2010 & 2011 & 2012 & 2013 & 2014 \\
\hline IV & 30 & 63 & 15 & 8 & 11 & 39 & 42,2 & 72,1 \\
\hline $\mathrm{V}$ & 70 & 16 & 66 & 109 & 57 & 16 & 51,1 & 52,5 \\
\hline $\mathrm{VI}$ & 132 & 64 & 97 & 47 & 86 & 89 & 64,4 & 55,9 \\
\hline VII & 188 & 56 & 103 & 79 & 107 & 119 & 54,5 & 37,9 \\
\hline VIII & 78 & 131 & 56 & 201 & 118 & 100 & 52,3 & 83,6 \\
\hline IX & 98 & 35 & 99 & 74 & 53 & 103 & 85,4 & 54,4 \\
\hline $\mathrm{X}$ & 50 & 65 & 121 & 30 & 70 & 71 & 44,3 & 30,6 \\
\hline Suma (IV-X) - Sum (IV-X) & 646 & 430 & 557 & 548 & 502 & 537 & 394,2 & 387,0 \\
\hline Suma (I-XII) - Sum (I-XII) & 1014 & 742 & 761 & 802 & 698 & 832 & 615,9 & 588,9 \\
\hline
\end{tabular}

Tabela 2. Współczynnik hydrotermiczny Sielianinowa w Koszalinie w latach 2007-2014

Table 2. Hydrothermal Sielianinow coefficient in Koszalin in the years 2007-014

\begin{tabular}{|c|c|c|c|c|c|c|c|c|}
\hline \multirow{2}{*}{$\begin{array}{l}\text { Miesiąc } \\
\text { Month }\end{array}$} & \multicolumn{8}{|c|}{$\begin{array}{l}\text { Współczynnik Sielianinowa }(\mathrm{K}) \text { w latach } \\
\text { Sielianinow coefficient }(\mathrm{K}) \text { in the years }\end{array}$} \\
\hline & 2007 & 2008 & 2009 & 2010 & 2011 & 2012 & 2013 & 2014 \\
\hline IV & 1,14 & 2,88 & 0,48 & 0,38 & 0,37 & 1,73 & 2,07 & 2,50 \\
\hline $\mathrm{V}$ & 1,64 & 0,42 & 1,80 & 3,74 & 1,44 & 0,39 & 1,19 & 1,37 \\
\hline VI & 2,56 & 1,33 & 2,33 & 1,06 & 1,74 & 1,99 & 1,37 & 1,23 \\
\hline VII & 3,57 & 1,01 & 1,82 & 1,25 & 2,02 & 2,18 & 0,98 & 0,59 \\
\hline VIII & 1,41 & 2,41 & 0,99 & 3,56 & 2,19 & 1,85 & 0,93 & 1,56 \\
\hline IX & 2,51 & 0,90 & 2,28 & 1,91 & 1,20 & 2,42 & 2,21 & 1,19 \\
\hline $\mathrm{X}$ & 1,94 & 2,23 & 5,27 & 1,38 & 2,30 & 2,60 & 1,36 & 0,88 \\
\hline $\begin{array}{c}\text { Średnia ważona (IV-X) } \\
\text { Weighted average (IV-X) }\end{array}$ & 2,20 & 1,51 & 1,92 & 1,99 & 1,67 & 2,01 & 1,34 & 1,24 \\
\hline
\end{tabular}

Tabela 3. Wpływ badanych czynników na zmienność zamierania karp wierzby

Table 3. Effect of studied factors on the variability of willow bushes withering

\begin{tabular}{|c|c|c|c|c|c|c|}
\hline \multirow[t]{2}{*}{$\begin{array}{l}\text { Komponent wariancyjny } \\
\text { Variance component }\end{array}$} & \multirow[t]{2}{*}{$\begin{array}{l}\text { Poziomy } \\
\text { czynnika } \\
\text { Factor } \\
\text { levels }\end{array}$} & \multirow{2}{*}{$\begin{array}{l}\text { Struktura procentowa } \\
\text { komponentów } \\
\text { wariancyjnych } \\
\text { Percentage structure } \\
\text { of variance components }\end{array}$} & \multicolumn{4}{|c|}{$\begin{array}{l}\text { Udział czynników głównych } \\
\text { w zmienności interakcji } \\
\text { Contribution of main factors } \\
\text { in the variability of interaction }\end{array}$} \\
\hline & & & A & $\mathrm{B}$ & $\mathrm{C}$ & $\mathrm{D}$ \\
\hline 1 & 2 & 3 & 4 & 5 & 6 & 7 \\
\hline $\begin{array}{l}\text { Odmiany i klony wierzby } \\
\text { Willow cultivars and clones [D] }\end{array}$ & 10 & $6,9^{* *}$ & & & & 6,9 \\
\hline Gęstość sadzenia - Planting density [C] & 3 & $6,8 * *$ & & & 6,8 & \\
\hline $\begin{array}{l}\text { Częstotliwość koszenia wierzby } \\
\text { Frequency of willow harvesting [B] }\end{array}$ & 2 & $1,9^{* *}$ & & 1,9 & & \\
\hline $\begin{array}{l}\text { Wiek uprawy = lata odrastania pędów } \\
\text { Age of the cultivation = years of shoots } \\
\text { regrowth [A] }\end{array}$ & 8 & $37,9 * *$ & 37,9 & & & \\
\hline Współdziałanie DC - Interation DC & & $4,7 * *$ & & & 2,35 & 2,35 \\
\hline Współdziałanie DB - Interation DB & & $2,8 * *$ & & 1,4 & & 1,4 \\
\hline Współdziałanie CB - Interation CB & & $1,0^{*}$ & & 0,5 & 0,5 & \\
\hline Współdziałanie DCB - Interation DCB & & $3,9 * *$ & & 1,3 & 1,3 & 1,3 \\
\hline Współdziałanie DA - Interation DA & & $7,3 * *$ & 3,65 & & & 3,65 \\
\hline Współdziałanie CA - Interation CA & & $5,4 * *$ & 2,7 & & 2,7 & \\
\hline
\end{tabular}




\begin{tabular}{|c|c|c|c|c|c|c|}
\hline 1 & 2 & 3 & 4 & 5 & 6 & 7 \\
\hline Współdziałanie DCA - Interation DCA & & $3,3 * *$ & 1,1 & & 1,1 & 1,1 \\
\hline Współdziałanie BA - Interation BA & & $4,6 * *$ & 2,3 & 2,3 & & \\
\hline Współdziałanie DBA - Interation DBA & & $7,8 * *$ & 2,6 & 2,6 & & 2,6 \\
\hline Współdziałanie CBA - Interation CBA & & $1,0 * *$ & 0,33 & 0,33 & 0,34 & \\
\hline Współdziałanie DCBA - Interation DCBA & & 4,7 & 1,175 & 1,175 & 1,175 & 1,175 \\
\hline Suma - Sum & & 100,0 & 51,755 & 11,505 & 16,265 & 20,475 \\
\hline
\end{tabular}

Istotność przy poziomie: ${ }^{*} \alpha=0,05 ;{ }^{* *} \alpha=0,01-$ Significance at: ${ }^{*} \alpha=0.05 ; * * \alpha=0.01$

Tabela 4. Wpływ współdziałania lat odrastania pędów z odmianami na zamieranie karp wierzby

Table 4. Effect of interaction of years of regrowth with the cultivars on the withering of willow bushes

\begin{tabular}{|c|c|c|c|c|c|c|c|c|c|c|c|}
\hline \multirow{2}{*}{$\begin{array}{l}\text { Wiek uprawy } \\
\text { Age of the cultivation }\end{array}$} & \multicolumn{11}{|c|}{$\begin{array}{l}\text { Procent zamarłych karp u klonów i odmian wierzby } \\
\text { Percent of withered bushes from clones and cultivars willow }\end{array}$} \\
\hline & 1047 & 1054 & 1047D & Start & Sprint & Turbo & Ekotur & Olof & Jorr & Tordis & $\begin{array}{c}\text { średnia } \\
\text { mean }\end{array}$ \\
\hline 1 & 1,0 & 2,0 & 3,1 & 0,6 & 0,0 & 1,3 & 0,3 & 11,0 & 4,6 & 3,2 & 2,7 \\
\hline 2 & 5,2 & 4,6 & 3,3 & 1,0 & 0,0 & 4,3 & 1,7 & 14,9 & 10,6 & 6,5 & 5,2 \\
\hline 4 & 7,7 & 3,4 & 5,7 & 4,1 & 0,8 & 6,6 & 2,9 & 14,6 & 13,9 & 6,2 & 6,6 \\
\hline 6 & 19,7 & 21,3 & 21,0 & 38,7 & 25,9 & 14,5 & 6,6 & 30,4 & 20,6 & 8,4 & 20,7 \\
\hline 8 & 29,0 & 29,1 & 34,0 & 57,4 & 41,5 & 34,4 & 23,5 & 40,1 & 41,0 & 30,6 & 36,1 \\
\hline $\begin{array}{l}\operatorname{NIR}(0,05) \\
\operatorname{LSD}(0.05)\end{array}$ & \multicolumn{10}{|c|}{$4,4^{*}$} & $1,4^{*}$ \\
\hline $\begin{array}{l}\text { Srednia dla odmian } \\
\text { Mean for cultivars }\end{array}$ & 13,2 & 12,9 & 12,8 & 19,0 & 12,1 & 11,8 & 6,5 & 22,9 & 17,9 & 10,5 & 14,0 \\
\hline $\begin{array}{l}\operatorname{NIR}(0,05) \\
\operatorname{LSD}(0.05)\end{array}$ & \multicolumn{10}{|c|}{$1,6^{*}$} & - \\
\hline
\end{tabular}

Istotność przy poziomie: ${ }^{*} \alpha=0,01-$ Significance at: $* \alpha=0.01$

- u klonów i odmian: 1047, 1054, 1047D, Start, Sprint, Turbo, a w ósmym roku - u odmian Ekotur i Tordis.

Odmiany wierzby charakteryzowały się zróżnicowaną skłonnością do zamierania karp (tab. 4). Przeciętnie na doświadczeniu w okresie ośmiu lat zamarło 14\% karp. Istotnie najmniej karp zamarło u odmiany Ekotur (przeciętnie 6,5\%) i Tordis (przeciętnie 10,5\%), a najwięcej u odmian: Olof (przeciętnie 22,9\%) i Start (przeciętnie 19,0\%). Nasilone zamieranie karp zaobserwowano w szóstej wegetacji poza odmianami Ekotur i Tordis oraz w 7. i 8. u wszystkich odmian. W ósmej wegetacji uszeregowanie odmian i klonów pod względem ich skłonności do zamierania karp było następujące: bardzo silne - Olof (22,9\%), silne - Start $(19,0 \%)$ i Jorr $(17,9 \%)$, średnie - 1047 (13,2\%), 1054 (12,9\%), 1047D (12,8\%), Sprint (12,1\%), Turbo $(11,8 \%)$ i Tordis $(10,5 \%)$ oraz małe - Ekotur $(6,5 \%)$.

Wpływ gęstości sadzenia zrzezów i współdziałania tego czynnika z odmianami wierzby zestawiono w tabeli 5 . Przeciętnie dla 8-letniej uprawy wierzby przy sadzeniu zrzezów w ilości 15020 i 22134 szt./ha zamarło istotnie mniej karp (11,2-11,3\%) niż przy sadzeniu 33200 szt./ha $(19,3 \%)$. U wszystkich odmian i klonów wierzby istotnie najwięcej karp zamarło przy gęstości sadzenia 33200 szt./ha, a przy mniejszym zagęszczeniu wystąpiła specyficzna reakcja odmian i klonów. U czterech genotypów (1047, Turbo, Jorr i Tordis) najmniej zamarłych karp było przy gęstości sadzenia 22134 szt./ha, a u sześciu (1054, 1047G, Start, Sprint, Ekotur i Olof) - przy zagęszczeniu zrzezów 15020 szt./ha.
Wpływ częstotliwości zbioru w I rotacji i współdziałania tego czynnika z odmianami zestawiono w tabeli 6 . Przy 1-krotnym koszeniu (II rząd poletka) zamarło przeciętnie $12,2 \%$ karp, a przy 2-krotnym - 15,7\% (I rząd), tj. 1,29-krotnie więcej. Uszeregowanie odmian i klonów pod względem wzrostu ilości zamarłych karp z powodu 2-krotnego koszenia w stosunku do 1-krotnego koszenia, od największych wartości do najmniejszych, było następujące: Start (1,97-krotnie), Sprint (1,76-krotnie), 1047D (1,37-krotnie), 1047 (1,32-krotnie), 1054 i Turbo (1,29-krotnie), Olof (1,28-krotnie), Ekotur (1,10-krotnie), Jorr (0,89-krotnie) i Tordis (0,79-krotnie). Oceny te klasyfikują odmiany i klony pod względem reakcji na zamieranie karp przy zwiększonej częstotliwości koszenia jako: bardzo silnie reagujące - Start $(12,4 \%)$, silnie reagujące Sprint $(6,7 \%)$ i Olof $(5,6 \%)$, średnio reagujące - 1047D $(4,0 \%), 1047(3,7 \%), 1054(3,3 \%)$ i Turbo (3,0\%), mało reagujące - Ekotur $(0,6 \%)$ oraz niereagujące - Jorr $(-2,1 \%)$ i Tordis $(-2,5 \%)$.

W literaturze polskiej podawane są różne wielkości optymalnej obsady karp wierzby na plantacji: 30-32 tys./ha (Dubas i Tomczyk 2005), 17,6-22,0 tys./ha (Faber i wsp. 2009), 18-20 tys./ha (Szczukowski i wsp. 2004), 10-20 tys./ha (Szczukowski 2012). Szczukowski i wsp. (2004) zalecają, aby przy zbiorze w cyklach jednorocznych sadzić 40-60 tys. zrzezów na hektarze, gdyż zwiększenie obsady z 20 do 40-60 tys./ha zwiększa plon świeżej biomasy. Faber i wsp. (2009) podają, aby sadzić zrzezy wierzby na glebach słabszych - 22,0 tys./ha, a na żyźniejszych $-17,6$ tys./ha, gdyż w badaniach szwedzkich i an- 
Tabela 5. Wpływ współdziałania gęstości sadzenia na poletku z klonami i odmianami na zamieranie karp wierzby

Table 5. Effect of interaction of planting density in the plot with the clones and cultivars on the withering of willow bushes

\begin{tabular}{|c|c|c|c|c|c|c|c|c|c|c|c|}
\hline \multirow{2}{*}{$\begin{array}{c}\text { Gęstość sadzenia } \\
\text { [sztuk/ha] } \\
\text { Planting density } \\
\text { [pcs/ha] }\end{array}$} & \multicolumn{11}{|c|}{$\begin{array}{l}\text { Procent zamarłych karp u klonów i odmian wierzby } \\
\text { Percent of withered bushes from clones and cultivars willow }\end{array}$} \\
\hline & 1047 & 1054 & 1047D & Start & Sprint & Turbo & Ekotur & Olof & Jorr & Tordis & $\begin{array}{c}\text { średnia } \\
\text { mean }\end{array}$ \\
\hline 15020 & 12,5 & 6,7 & 7,2 & 13,8 & 8,3 & 14,4 & 0,8 & 19,6 & 22,2 & 6,7 & 11,2 \\
\hline 22134 & 6,6 & 13,8 & 10,2 & 20,0 & 11,3 & 3,4 & 6,0 & 23,2 & 13,4 & 5,3 & 11,3 \\
\hline 33200 & 20,6 & 18,1 & 20,8 & 23,2 & 16,7 & 17,6 & 12,9 & 25,9 & 18,1 & 19,5 & 19,3 \\
\hline $\begin{array}{l}\text { NIR }(0,05) \\
\operatorname{LSD}(0.05)\end{array}$ & \multicolumn{10}{|c|}{$2,7^{*}$} & $0,9 *$ \\
\hline
\end{tabular}

Istotność przy poziomie: ${ }^{*} \alpha=0,01-$ Significance at: $* \alpha=0.01$

Tabela 6. Wpływ współdziałania częstotliwości koszenia wierzby na poletku z odmianami na zamieranie karp wierzby Table 6. Effect of interaction of frequency of willow harvesting in the plot with the cultivars on the withering of willow bushes

\begin{tabular}{|c|c|c|c|c|c|c|c|c|c|c|c|}
\hline \multirow{2}{*}{$\begin{array}{c}\text { Częstotliwość koszenia } \\
\text { wierzby } \\
\text { Frequency of willow } \\
\text { harvesting }\end{array}$} & \multicolumn{11}{|c|}{$\begin{array}{l}\text { Procent zamarłych karp u klonów i odmian wierzby } \\
\text { Percent of withered bushes from clones and cultivars willow }\end{array}$} \\
\hline & 1047 & 1054 & 1047D & Start & Sprint & Turbo & Ekotur & Olof & Jorr & Tordis & $\begin{array}{c}\text { średnia } \\
\text { mean }\end{array}$ \\
\hline $2 \times$ & 15,1 & 14,5 & 14,8 & 25,2 & 15,5 & 13,3 & 6,8 & 25,7 & 16,8 & 9,3 & 15,7 \\
\hline $1 \times$ & 11,4 & 11,2 & 10,8 & 12,8 & 8,8 & 10,3 & 6,2 & 20,1 & 18,9 & 11,8 & 12,2 \\
\hline $\begin{array}{l}\operatorname{NIR}(0,05) \\
\operatorname{LSD}(0.05)\end{array}$ & \multicolumn{10}{|c|}{$2,2 *$} & $0,7 *$ \\
\hline
\end{tabular}

Istotność przy poziomie: $*_{\alpha}=0,01-$ Significance at: $*_{\alpha}=0.01$

gielskich wykazano, że w korzystnych warunkach wilgotnościowych uzasadnione jest zmniejszenie obsady karp wierzby do 10-13 tys./ha. Według Caslin i wsp. (2010) w północnej Irlandii sadzi się 18 tys./ha zrzezów z wyliczeniem, że finalnie na plantacji komercyjnej pozostanie 15 tys./ha roślin. Podobne zalecenia co do gęstości sadzenia wierzby na cele energetyczne mają miejsce we wschodniej części Kanady (Guidi i wsp. 2013), Anglii, Szkocji, Szwecji (Defra 2004; Wickham i wsp. 2010). Spotykane w literaturze zachodniej zalecenia zagęszczenia łanu wierzby wynikają ze stosowanej tam technologii uprawy i różnią się od zaleceń dla warunków przyrodniczych Polski.

Jednak w literaturze brak jest wieloletnich obserwacji dotyczących zamierania karp wierzby na plantacjach. W Polsce przyjmuje się, że na założonej 1-rocznej plantacji udatność powinna wynosić ponad 85-95\% żywych karp w stosunku do zastosowanych nasadzeń (Dubas i Tomczyk 2005), a w warunkach Irlandii przy uprawie wierzby przyjmuje się ubytek 3 tys./ha roślin, tj. 17\% zrzezów wysadzonych.

Problem dynamiki zamierania karp wierzby poruszony był w pracach Stolarskiego (2009), Styszki i wsp. (2013) oraz Styszki i Ignatowicz (2014). Stolarski (2009) wykazał, że zamieranie karp wierzby w 3-letnim cyklu uprawy na glebie ciężkiej w okolicach Kwidzyna zależało od odmiany, gęstości sadzenia oraz częstotliwości zbioru, jednakże nie przekraczało ono $10 \%$ założonej obsady niezależnie od badanego wariantu. W warunkach uprawy na glebach lekkich pod Koszalinem w 4-letnim cyklu uprawy zamarło mniej niż 10\% karp, ale w siódmej wegetacji martwych karp na poletku było od 10 do $90,8 \%$ (Styszko i wsp. 2013). W cytowanych badaniach u czte- rech klonów przy nawożeniu kompostem $\mathrm{z}$ osadów komunalnych zamieranie karp malało, ale dodatkowe stosowanie nawozu mineralnego u wszystkich dziewięciu klonów, zwiększyło to zamieranie. W referowanych badaniach wykazano, że na dynamikę zamierania karp wierzby na poletkach największy wpływ miały lata uprawy, nieco mniejszy - częstotliwość koszenia, a najmniejszy - dawki azotu i odmiany. Również w badaniach polowych Styszki i Ignatowicz (2014) wykonanych w latach 2008-2013 wykazano, że na zamieranie karp wierzby duży wpływ miały lata odrastania pędów i częstotliwości zbioru pędów, a mniejsze - dawki azotu i odmiany. Do czwartego roku uprawy przeciętnie zamarło 5,3\% karp wierzby, a wzrost ilości martwych karp na poletku nastąpił w 5. i 6. wegetacji. W tych doświadczeniach wzrost dawki nawożenia azotem do $180 \mathrm{~kg} / \mathrm{ha} \mathrm{w}$ stosunku do obiektów bez nawożenia spowodował nasilenie zamierania karp wierzby. Na obiektach z 1-krotnym koszeniem w pierwszej 4-letniej rotacji zamarło przeciętnie 5,6\% karp, a przy 2-krotnym $14,1 \%$. Odmiany i klony wierzby uczestniczące w cytowanych badaniach pod względem ich reakcji na zamieranie karp przy zwiększonej częstotliwości koszenia zakwalifikowano jako: bardzo silnie reagujące - Sprint i Start, silnie reagujące - 1047D, 1054 i 1047, średnio reagujące - Jorr i Turbo oraz niereagujące - Olof, Tordis i Ekotur. W obecnie prezentowanych badaniach odmiany i klony wierzby pod względem ich skłonności do zamierania zakwalifikowano jako: bardzo silne - Start $(42,4 \%)$, silne - Sprint $(31,9 \%)$, średnie - 1054 (26,8\%), Jorr $(25,0 \%)$, Olof (24,1\%), 1047 (23,9\%), 1047D (23,7\%) i Turbo (20,6\%) oraz małe - Tordis $(13,6 \%)$ i Ekotur $(9,2 \%)$. 
Wszystkie cytowane badania pokazują skalę zjawiska, ale nie wskazują na biologiczne przyczyny zamierania karp. Można sądzić, że przyczyną zamierania karp w uprawie polowej są infekcje grzybowe roznoszone podczas zbioru, co może sugerować opracowanie Remlein-Starosty i Nijak (2010).

\section{Wnioski / Conclusions}

1. Na zamieranie karp wierzby duży wpływ ma wiek uprawy, gęstość sadzenia zrzezów i ich współdziałanie, a mniejsze znaczenie mają odmiany czy klony oraz częstotliwość zbioru pędów w I rotacji.

2. Po czwartej wegetacji przeciętnie zamarło $6,6 \%$ karp wierzby, a duży wzrost ilości martwych karp na poletku wystapił w następnych latach wegetacjach $(6-20,7 \%$, $8-36,1 \%)$.

3. Odmiany i klony zakwalifikowano pod względem skłonności do zamierania na: bardzo silne - Olof (22,9\%), silne - Start $(19,0 \%)$ i Jorr $(17,9 \%)$, średnie - 1047 (13,2\%), 1054 (12,9\%), 1047D (12,8\%), Sprint (12,1\%), Turbo $(11,8 \%)$ i Tordis $(10,5 \%)$ oraz małe - Ekotur $(6,5 \%)$.

4. Wzrost gęstości sadzenia zrzezów do ponad 22134 szt./ha spowodował nasilenie zamierania karp wierzby.

5. Na obiektach $\mathrm{z}$ 1-krotnym koszeniem w pierwszej 4-letniej rotacji zamarło przeciętnie 12,2\% karp, a przy 2-krotnym - 15,7\%.

6. Planuje się dalszą kontynuację badań w celu wyjaśnienia biologicznych przyczyn zamierania karp wierzby.

\section{Literatura / References}

Caslin B., Finnan J., McCracken A. 2010. Short Rotation Coppice Willow Best Practice Guidelines. http://www.seai.ie/Renewables/ Bioenergy/Willow_Best_Practice_Guide_2010.pdf. Belfast. [Accessed: 05.02.2015].

Defra. 2004. Growing Short Rotation Coppice. Defra Publications. London. http://www.biomassenergycentre.org.uk/pls/portal/ docs/PAGE/BEC_TECHNICAL/SOURCES\%20OF\%20BIOMASS/ENERGY\%20CROPS/SHORT\%20ROTATION\%20ENERGY \%20CROPS/SHORT\%20ROTATION\%20COPPICE/WILLOW\%20SHORT\%20ROTATION\%20COPPICE\%20(SRC)/SHORTROTATION-COPPICE TCM6-4262.PDF [Accessed: 05.02.2015].

Dubas J.W., Tomczyk A. 2005. Zakładanie, pielęgnacja i ochrona plantacji wierzb energetycznych. SGGW, Warszawa, 105 ss.

Faber A., Kuś J., Matyka M. 2009. Uprawa roślin na cele energetyczne. W\&B Wiesław Drzewiński, Warszawa, 28 ss.

Guidi W., Pitre F.E., Labresque M. 2013. Short-Rotation Coppice of Willows for the Production of Biomass in Eastern Canada. http://dx.doi.org/10.5772/51111 [Accessed: 05.02.2015].

GUS. 2010. Rocznik statystyczny rolnictwa. Agrometeorologia: 67-70.

GUS. 2014. Rocznik statystyczny rolnictwa. Agrometeorologia: 79-82.

Remlein-Starosta D., Nijak K. 2010. Najważniejsze choroby i szkodniki wierzby uprawianej na cele energetyczne i możliwości ich ograniczania. [The most import ant deseases and pest of short rotation willow and control possibility]. Progress in Plant Protection/Postępy w Ochronie Roślin 50 (2): 977-986.

Skowera B., Puła J. 2004. Skrajne warunki pluwiometryczne w okresie wiosennym na obszarze Polski w latach 1971-2000. Acta Agrophysica 3 (1): 171-177.

Stolarski J.M. 2009. Agrotechniczne i ekonomiczne aspekty produkcji biomasy wierzby krzewiastej (Salix spp.) jako surowca energetycznego. Wydawnictwo Uniwersytetu Warmińsko-Mazurskiego, Olsztyn, 145 ss.

Styszko L., Boguski A., Fijałkowska D. 2013. Wpływ nawożenia na zamieranie karp wierzby energetycznej przy uprawie na glebie lekkiej. Journal of Civil Engineering, Evironment and Architecture 30, 60 (3/13): 19-28.

Styszko L., Ignatowicz M. 2014. Wpływ odmian, częstotliwości zbioru i nawożenia azotem na zamieranie karp wierzby krzewiastej w 6-letnim cyklu uprawy. [Influence of varieties, harvest frequency and nitrogen fertilization on dieback of short rotation willow bushes in a six-year cultivation cycle]. Progress in Plant Protection/Postepy w Ochronie Roślin 54 (3): 261-266 .

Szczukowski S. 2012. Wierzba. s. 10-38. W: „Wieloletnie rośliny energetyczne” (S. Szczukowski, red.). MULTICO Oficyna Wydawnicza, Warszawa, 156 ss.

Szczukowski S., Tworkowski J., Stolarski M.J. 2004. Wierzba energetyczna. Plantpress, Kraków, 46 ss.

Wickham J., Rice B., Finnan J., McConnon R. 2010. A review of past and current research on short rotation coppice in Ireland and abroad. COFORD, Dublin. http://www.coford.ie/media/coford/content/publications/projectreports/SRC.pdf [Accessed: 05.02.2015]. 